\title{
Development of Monoclonal-antibody-ELISA, -DOT-BLOT and -DIP-STICK Immunoassays for Humicola lanuginosa in Rice
}

\author{
By F. M. DEWEY, ${ }^{*}$ M. M. MACDONALD† AND S. I. PHILLIPS ${ }^{2}$ \\ ${ }^{1}$ Department of Plant Sciences, University of Oxford, South Parks Road, Oxford OX1 3RA, UK \\ ${ }^{2}$ ODNRI, 56-62 Gray's Inn Road, London WCIX 8LU, UK
}

(Received 27 June 1988; revised 12 October 1988; accepted 24 October 1988)

\begin{abstract}
Monoclonal antibodies (MAbs) were raised against Humicola lanuginosa, a thermophilic, saprophytic fungus that is commonly isolated from freshly harvested rice grains in Indonesia. Mice were immunized by direct injection into the peritoneum, without prior concentration, of fresh cell-free surface washings from a solid agar slant culture. Hybridoma supernatants were screened by ELISA using wells coated with a dilution of the immunogen. From one fusion 403 hybridoma clones were obtained yielding 52 cell lines secreting antibodies positive for $H$. lanuginosa. Twelve cell lines were re-cloned, grown in bulk and tested against other storage fungi. Most of the MAbs raised were IgM antibodies that cross-reacted with several of the storage fungi and/or uninfected rice grains. However, the IgM antibody EC6 did not recognize antigens from rice grains and cross-reacted strongly with only one other test fungus, Penicillium variabile, and partially with two others. This MAb was used to develop a highly sensitive DIPSTICK immunoassay to detect the fungus in infected grains. These assays are simple to perform, require no equipment and are suitable for field use by untrained workers.
\end{abstract}

\section{INTRODUCTION}

Micro-organisms, particularly fungi, contribute to the post-harvest deterioration of rice. The growth of fungi may adversely affect the nutritional value, colour, flavour and texture of the grain, result in grain weight loss, cause heating and pose a hazard to the health of humans and animals by the production of mycotoxins (Christensen \& Sauer, 1982). One problem, common in South-East Asian rice, is a yellow discolouration of the grain which results in economic losses and arouses concern over toxicity (de Padua, 1977). Yellowing of harvested rough rice can occur before and during drying as well as in storage (Phillips et al., 1984). Most yellowing occurs in heaps or bags of wet rough rice or stalk paddy awaiting drying. Under these conditions a high incidence of yellowing may result from heating of the grains at high moisture content caused by the growth of fungi. Fungi typically isolated from wet rough rice are the mesophilic and thermotolerant species: Aspergillus flavus Link et Fries, $A$. candidus Link, A. fumigatus Fresenius and species of Rhizopus Ehrenb and Mucor Lind. Humicola lanuginosa (Griffon and Maublanc) Bunce, a thermophilic fungus, is prevalent in heating wet rice (S. I. Phillips et al., unpublished). Penicillia such as $P$. islandicum Sopp, $P$. purpurogenum Stoll and $P$. miczynskii Zaleski may be more common in stored rice (Phillips et al., 1988).

It is difficult to determine rapidly the extent of growth of the suspect fungi, either on the husk or within the rice grains, by light microscopy and classical isolation procedures. Early detection is impossible by conventional techniques. A quick assay such as an immunological assay is needed. Some attempts have been made to detect and quantify fungi in stored cereals and rice grains by immunological techniques using polyclonal antisera (see review by Clarke et al., 1986).

† Present address: Biotechnology/Research State Chemistry Laboratory, East Melbourne, Victoria 3002, Australia.

Abbreviations: FBS, foetal bovine serum; PBS, phosphate-buffered saline; PBST, PBS with 0.05\% Tween 20; TBS, Tris-buffered saline; PVDF, polyvinylidene difluoride; TCMC, tissue culture medium control. 
These methods have not proved useful because antisera to fungi cross-react widely with other fungi and host tissues when tested by ELISA and immunofluorescent techniques (Dewey et al., 1984; Dewey \& Brasier, 1988; Chard et al., 1985; Clarke et al., 1986) and efforts to increase specificity by cross-adsorption have not been satisfactory (Chard et al., 1985; Clarke et al., 1986). Specificity has only been increased where antisera have been raised against selected fungal molecules such as 'genus-specific' carbohydrates (Notermans et al., 1987). However, subspecies-, species- and genus-specific monoclonal antibodies (MAbs) have been raised against zoospores of Phytophthora and Pythium (Hardham et al., 1986; Callow et al., 1987) and mycelial fragments of Ophiostoma ulmi (Dewey et al., 1989). In the case of $O$. ulmi such antibodies have been used to detect and quantify the pathogen in diseased woody tissue by ELISA.

There are few, if any, reports on membrane-MAb diagnostic assays for detection of fungi in plant tissues. Such assays are particularly attractive because of their simplicity and could therefore be done under field conditions by untrained workers. This paper concerns the production of MAbs that recognize $H$. lanuginosa and the detection of this fungus both on and within infected rice grains by immunoassay. The presence of the fungus in naturally infected grain was verified by freeze-fracture scanning electron microscopy.

\section{METHODS}

Rice samples. Samples of rough rice were collected during field visits to Indonesia in 1983 and 1984. Commercial milled rice samples purchased in the UK were also used for inoculation work with fungi in the laboratory.

Cultures of fungi. All cultures of fungi (Table 1) were originally isolated by a direct plating technique (Phillips $e t$ al., 1988) from naturally infected grains collected from dry stored rough rice or wet rough rice heaps in Indonesia. Isolates were maintained in pure culture on agar slants. Rice was inoculated by the following procedure. Samples $(30 \mathrm{~g})$ of rice were sterilized $\left(121^{\circ} \mathrm{C}\right.$ for $\left.30 \mathrm{~min}\right)$ in $100 \mathrm{ml}$ conical flasks. The moisture content of the rice was then adjusted to $23-26 \%$ using sterile distilled water. The rice was left to condition for 1 week at $0{ }^{\circ} \mathrm{C}$. Spore suspensions of fungi were prepared in $10 \mathrm{ml}$ volumes (Pitt, 1979) using 5-d-old cultures. A suspension of spores $(0.5 \mathrm{ml})$ was inoculated into each flask, mixed thoroughly and placed in a shaking incubator at $30^{\circ} \mathrm{C}\left(45^{\circ} \mathrm{C}\right.$ for $\mathrm{H}$. lanuginosa) for up to $10 \mathrm{~d}$. The rice conditioning and inoculation procedure was the same for $500 \mathrm{~g}$ of rice $(2.5 \mathrm{ml}$ of spore

Table 1. Details of fungal cultures and growth conditions

\section{Culture}

Aspergillus amstelodami (Mang.) Thom and Church Aspergillus candidus Link

Aspergillus flavus Link

Aspergillus fumigatus Fresenius

Aspergillus penicillinoides Stegazzini

Aspergillus restrictus Smith

Aspergillus ruber Estienne

Corynascus sepedonium (Emmos) v. Arx

Eupenicillium javanicum (van Beyrna) Stolk and Scott

Fusarium graminearum Schwabe

Humicola lanuginosa (Griffon and Maublanc) Bunce

Humicola insolens Cooney and Emerson

Mucor pusillus Lind +

Penicillium citrinum Thom

Penicillium diversum var. aureum Raper and Fennel

Penicillium islandicum Sopp

Penicillium sp. isolate $\mathrm{X}^{*}$

Penicillium sp. isolate $\mathrm{XCII}^{*}$

Penicillium sp. isolate DFNG*

Penicillium miczynskii Zaleski

Penicillium purpurogenum Stoll

Penicillium variabile Sopp

Thermomyces stellata

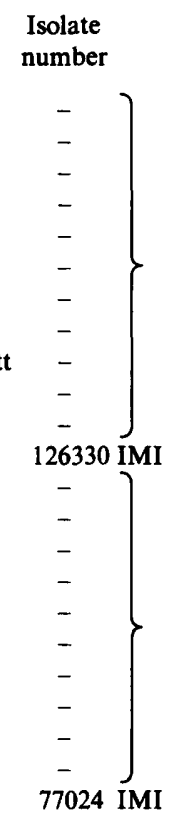

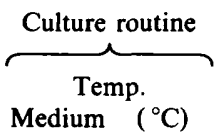

MY40

YSA

YSA

MEA

Naturally infected grain, MY40

Indonesia. Isolated

MY40

MY40

YSA

MEA

YSA

YSA

YSA

YSA

MEA

MEA

Naturally infected grain, MEA

MEA

MEA

MEA

MEA

MEA

YSA

YSA
30

30
30

30

30

30

30

30

30

30

30

45

45

30

30

30

30

30

30

30

30

30

30

30

- Three isolates of an unnamed species of Penicillium. 
suspension) used in an experiment to stimulate natural heating of rice in a 1 litre water-jacketed vessel. Isolates were subcultured on agar slants in $30 \mathrm{ml}$ Universal plastic tubes containing $10 \mathrm{ml}$ agar per tube.

Preparation of the immunogen and immunization protocol. In this study, antibodies that recognize surface molecules of the fungus were raised by a simple direct method. Cell-free surface washings of a mycelial colony growing on an agar slant were used as the immunogen. Cultures (5-d-old) of $\boldsymbol{H}$. lanuginosa grown on yeast starch agar slants (YSA) (Cooney \& Emerson, 1964) at $45^{\circ} \mathrm{C}$ were washed briefly with $2 \mathrm{ml}$ phosphate-buffered saline (PBS; $0.8 \% \mathrm{NaCl}, 0.02 \% \mathrm{KCl}, 0.115 \% \mathrm{Na}_{2} \mathrm{HPO}_{4}, 0.02 \% \mathrm{KH}_{2} \mathrm{PO}_{4}, \mathrm{pH} 7.2$ ). To help wet the hydrophobic surface of the culture, the mycelial surface was gently stroked with a sterile plastic pipette tip. The resulting fluid, approximately $1 \mathrm{ml}$, was removed by suction, placed in an Eppendorf tube and spun in a microfuge for $2 \mathrm{~min}$ at $13250 \mathrm{~g}$ to remove cell debris, and then used immediately as the immunogen. This solution contained $0.4 \mathrm{mg}$ protein $\mathrm{ml}^{-1}$ as determined by the micro-Lowry method (see below).

Two female Balb/C mice (6-weeks-old) were given five intraperitoneal injections of $300 \mu \mathrm{l}$ of the immunogen at $0,2,4,32$ and 54 weeks. Mice were bled from the tail vein 4 or $5 \mathrm{~d}$ after both the second and third injections.

Production of hybridomas. Cells of the myeloma cell line SP2/0-Ag14 were grown in RPMI 1640 (Flow Labs) supplemented with $10 \%(\mathrm{v} / \mathrm{v})$ foetal bovine serum (FBS) in a humid atmosphere containing $5 \%(\mathrm{v} / \mathrm{v}) \mathrm{CO}_{2}$ at $37^{\circ} \mathrm{C}$.

The method used for fusing myeloma cells and splenocytes, except where noted, was based on the modification by Kennett et al. (1978) of the original method pioneered by Kohler \& Milstein (1975). The spleen of an immunized mouse was removed $4 \mathrm{~d}$ after the last (booster) injection, suspended in $20 \mathrm{ml}$ RPMI medium supplemented with FBS and ruptured by tearing apart with sterile needles. All the splenocytes from one mouse (approximately $10^{8}$ ) were fused with approximately $10^{7}$ actively growing myeloma cells. Cells were centrifuged separately at $250 \mathrm{~g}$ for 5 min, washed in RPMI without FBS, pooled, spun and gently resuspended and maintained in $33 \%$ (w/v) PEG 1500 , in serum-free RPMI for 7 min including a 2 min spin at $500 \mathrm{~g}$. The PEG supernatant was removed, the cells slowly resuspended in $5 \mathrm{ml}$ non-supplemented RPMI and finally further diluted into $45 \mathrm{ml} \mathrm{RPMI} \mathrm{with} 20 \%$ (v/v) FBS and plated out into ten 96-well trays at $50 \mu \mathrm{l}$ per well. After $24 \mathrm{~h} 50 \mu \mathrm{l}$ of selective medium containing doublestrength hypoxanthine azaserine (HAZA) (Foung et al., 1982) was added to each well. Wells were fed at 3 or $4 \mathrm{~d}$ intervals by adding $50 \mu \mathrm{l}$ of selective medium; after 7 to $10 \mathrm{~d}$ wells containing clones were identified and supernatants assayed for antibodies by ELISA. Positive clones were subsequently fed with non-selective medium and, when cells became confluent, they were transferred, successively, to 24- and then to 6-well plates. Supernatants were further tested against surface antigens of other fungi. Selected cell lines were re-cloned, grown in bulk, preserved by freezing slowly in FBS/DMSO $(92: 8, \mathrm{v} / \mathrm{v})$ and maintained in liquid nitrogen.

Protein determinations. An adaptation of the Lowry assay was used, in which $20 \mu \mathrm{l}$ samples were thoroughly mixed in microtitre wells with $200 \mu \mathrm{l}$ of a freshly prepared solution of $2 \%(\mathrm{w} / \mathrm{v}) \mathrm{Na}_{2} \mathrm{CO}_{3}, 0 \cdot 5 \%(\mathrm{w} / \mathrm{v}) \mathrm{CuSO}_{4} .5 \mathrm{H}_{2} \mathrm{O}$ and $1 \%(\mathrm{w} / \mathrm{v})$ potassium sodium tartrate $(48: 1: 1$, by vol.). After $10 \mathrm{~min}, 20 \mu \mathrm{l}$ of a $1: 1$ dilution of Folin and Ciocalteu's reagent in distilled water was added and thoroughly mixed by repeated pipetting of the mixture up and down in the wells. The absorbance was read after $30 \mathrm{~min}$ on a Titertek miniscan at $492 \mathrm{~nm}$ blanked against air.

Immunoassays. ELISA. Screening assays used for detection of $\boldsymbol{H}$. lanuginosa positive antibodies in hybridoma supernatants, were as described previously (Dewey \& Brasier, 1988). All test volumes were $50 \mu 1$ per well and all solutions were prepared in glass or polypropylene tubes. Wells were coated overnight at $4{ }^{\circ} \mathrm{C}$ with a 20 -fold dilution of the immunogen (antigen) in PBS, washed three times with PBST (PBS with 0.05\% Tween 20) and once with PBS, and then rinsed briefly in distilled water. Plates were air-dried in a laminar flow hood, sealed in polythene bags and stored at $4{ }^{\circ} \mathrm{C}$ for up to 6 weeks. Wells were incubated at room temperature for $2 \mathrm{~h}$ with primary antibody, washed three times with PBST and then incubated for $1 \mathrm{~h}$ with the secondary antibody conjugate [Sigma no. 0412 , goat anti-mouse polyvalent $(\mathrm{IgM}+\mathrm{IgG})$ peroxidase conjugate diluted 200 -fold in PBST], washed again with PBST and incubated with the substrate, tetramethylbenzidene, for $30 \mathrm{~min}$. The reaction was stopped by adding $2.5 \mathrm{M}^{-} \mathrm{H}_{2} \mathrm{SO}_{4}$ and the absorbance read immediately at $450 \mathrm{~nm}$ on a Titertek miniscan.

The final form of diagnostic ELISA test used for routine testing of natural rice samples was essentially the same procedure as that used for the detection of antibodies in hybridoma supernatants. Wells were passively coated with fungal antigens that had diffused out of infected grains soaked individually, overnight, in microtitre wells. In order to immerse grains totally in coating buffer, $150 \mu$ volumes were used, and therefore all subsequent reactant volumes were $150 \mu \mathrm{l}$, but otherwise the procedure was exactly the same as for hybridoma screening assays.

DOT-BLOT. Two membranes, both from Millipore, were tested: nitrocellulose and polyvinylidene difluoride (PVDF). The latter, known as Immobilon II, proved superior and was used for all the membrane assays reported here. Fungal antigens from infected rice grains were allowed to diffuse into solution by soaking grains individually, overnight in $200 \mu \mathrm{l}$ PBS in Eppendorf tubes at $4{ }^{\circ} \mathrm{C}$. Droplets $(3 \mu \mathrm{l})$ of the diffusate were then spotted onto pre-wetted PVDF membrane. The membrane was pre-wetted by rinsing in methanol and soaking for $5 \mathrm{~min}$ in double-distilled water. After the antigen had been allowed to air-dry onto the membrane for 15 min at room temperature, it was re-wetted in methanol, blocked with a $5 \%(\mathrm{w} / \mathrm{v})$ solution of BSA in Tris-buffered saline (TBS; $20 \mathrm{~mm}$-Tris/ $\mathrm{HCl}$, pH 8.2, $0 \cdot 9 \% \mathrm{NaCl}, 0 \cdot 1 \% \mathrm{BSA}, 20 \mathrm{~mm}$-sodium azide) for $30 \mathrm{~min}$, washed three times with TBS, 5 min each time, and then exposed to the undiluted primary antibody for $2 \mathrm{~h}$. After further washing, the blots 


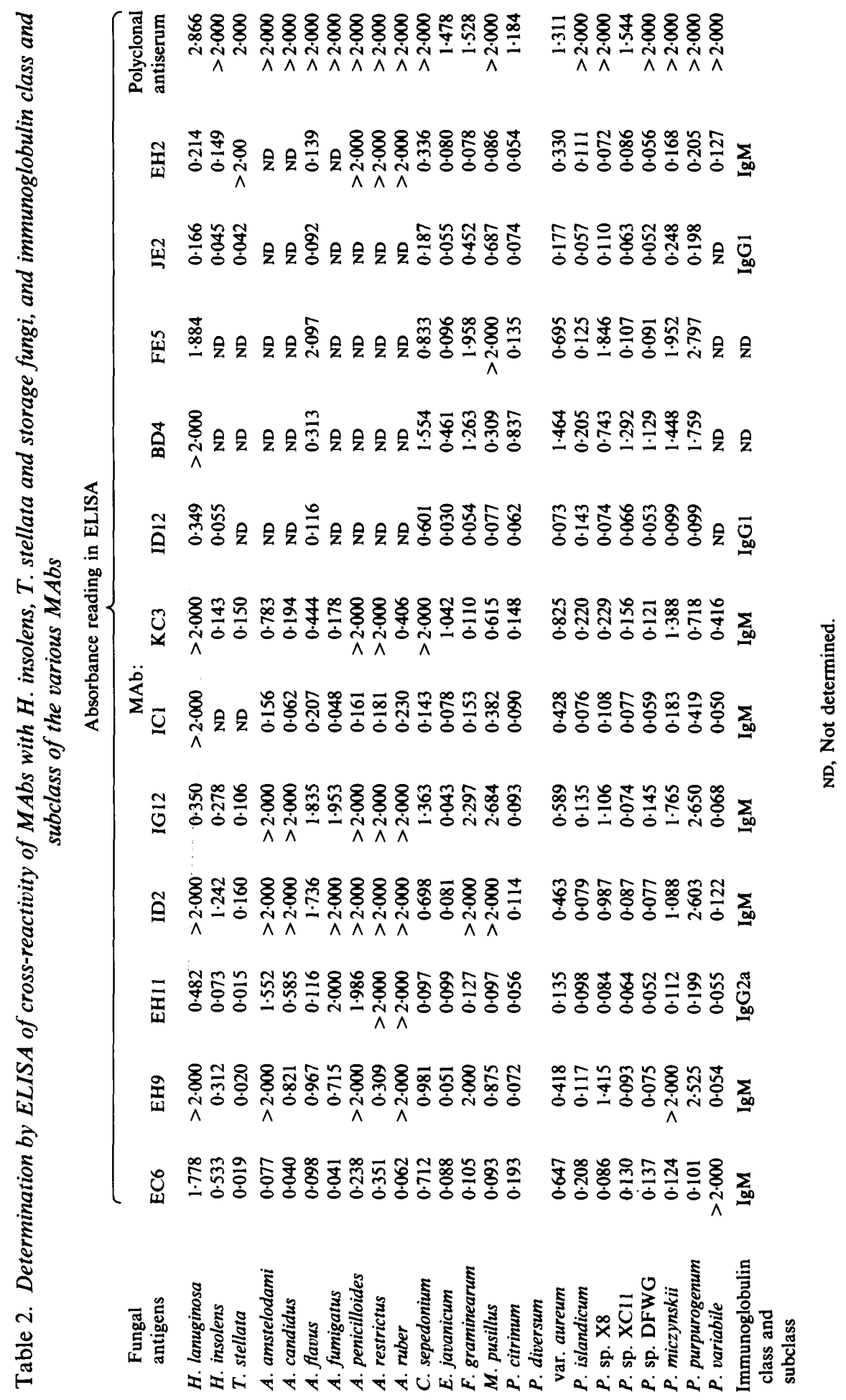


were incubated with Janssen goat anti-mouse IgG + IgM gold conjugate, washed again, treated with Janssen silver enhancer (Intense II) for a maximum of $30 \mathrm{~min}$ and finally washed in several changes of double-distilled water. All buffers, incubation times and dilution of the conjugate were as advised by Janssen in their protocol for processing dot-blots. Incubations and washings were done at room temperature on a rocking table.

DIP-STICK. Pre-wetted strips, $2 \times 25 \mathrm{~mm}$, of PVDF membrane were soaked overnight in Eppendorf tubes containing individual rice grains immersed in $200 \mu$ PBS. After removal the strips were air-dried and processed collectively in Universal tubes by the same method as that used for the DOT-BLOTS.

$S Q U A S H-B L O T$. Rough rice grains that had soaked overnight in PBS for the DIP-STICK assay were pressed onto the surface of a pre-wetted PVDF membrane before and after removal of the husks.

Determination of immunoglobulin subclass. A modified ELISA test was used. Wells were coated overnight with a 10000 -fold dilution of Sigma (no. M 8019) goat antimouse IgG + IgM in PBS. Subsequently wells were incubated with test hybridoma supernatants for $2 \mathrm{~h}$, and then probed with a 5000-fold dilution of one of the goat anti-mouse peroxidase conjugates, in PBST, that was specific for one of subclasses IgG1, IgG2a, IgG2b, IgG3 or IgM (Nordic isotyping subclass specific conjugate).

Heat and periodate treatment of antigens. To determine if the antigens were heat stable, wells were coated with surface washings from $H$. lanuginosa that had been diluted 20 -fold into PBS, autoclaved at $120^{\circ} \mathrm{C}$ for 15 min and then centrifuged for $2 \mathrm{~min}$ at $13250 \mathrm{~g}$ in a microfuge to remove any precipitate. Sensitivity of antigens to periodate treatment was determined by first blocking normally coated wells for 20 min with $0.5 \%$ BSA in PBS followed by incubation for $24 \mathrm{~h}$ at $4{ }^{\circ} \mathrm{C}$ with $20 \mathrm{~mm}$-sodium periodate in $50 \mathrm{~mm}$-sodium acetate buffer, $\mathrm{pH} 4 \cdot 5$. Control wells were incubated with sodium acetate buffer only. After periodate/buffer treatment wells were washed three times for $5 \mathrm{~min}$ with PBS containing $0.5 \% \mathrm{BSA}$, before incubation with the primary antibody.

Scanning electron microscopy. Sample blocks from 5- and 10-d-old colonies of $\boldsymbol{H}$. lanuginosa grown on slants were excised with a scalpel and attached to a specimen holder with colloidal graphite (Agar Aids). Healthy, naturally infected and inoculated grains, with and without husks (and milled) were attached by the same method and examined. The samples were rapidly frozen in nitrogen slush (Umrath, 1974) and transferred under vacuum first to the prechamber of an EMscope SP2000 Sputter-Cryo low-temperature preparation system when some grains were transversely fractured. All samples were etched for $6 \mathrm{~min}$ at a pressure of $1.3 \mathrm{~Pa}$ and gold-coated for a minimum of $3 \mathrm{~min}$ at $30 \mathrm{~mA}$ before transfer to an SEM cold stage for microscope examination in a Cambridge Stereoscan 150 .

\section{RESULTS}

Titres of antisera from both mice were similar and high. End-dilution detection values for antisera tested by ELISA against fresh and autoclaved surface washings diluted 20 -fold into PBS were 1 in 104000 and 1 in 25000 respectively.

\section{Monoclonal antibodies}

From one fusion 403 hybridoma clones were obtained; 52 of these cell lines tested positively for $H$. lanuginosa giving absorbance values of $>0.4$; several of these supernatants gave higher absorbance values than the polyclonal antisera diluted 1000-fold into PBST. Twelve cell lines were re-cloned and tested against Humicola insolens, Thermomyces stellata, three isolates of an unnamed species of Penicillium (designated X8, XCII and DFNG) and 17 other storage fungi (Table 2). Supernatants from most cell lines were relatively non-specific, cross-reacting with

Table 3. Sensitivity to heat and periodate treatment of $H$. lanuginosa surface antigens as determined by ELISA

\begin{tabular}{lrcc} 
& \multicolumn{3}{c}{ Absorbance reading in ELISA } \\
\cline { 2 - 4 } MAb & Untreated & Heat treatment & Periodate treatment \\
TCMC & 0.040 & 0.028 & 0.043 \\
EC6 & 2.000 & 0.247 & 0.380 \\
EH9 & 1.237 & 0.540 & 1.190 \\
EH11 & 0.650 & 0.236 & 0.081 \\
ID2 & 1.968 & 0.946 & $>2.000$ \\
IG12 & $>2.000$ & 1.505 & $>2.000$ \\
KC3 & $>2.000$ & 0.247 & 0.550 \\
EH2 & $>2.000$ & 1.300 & $>2.000$
\end{tabular}




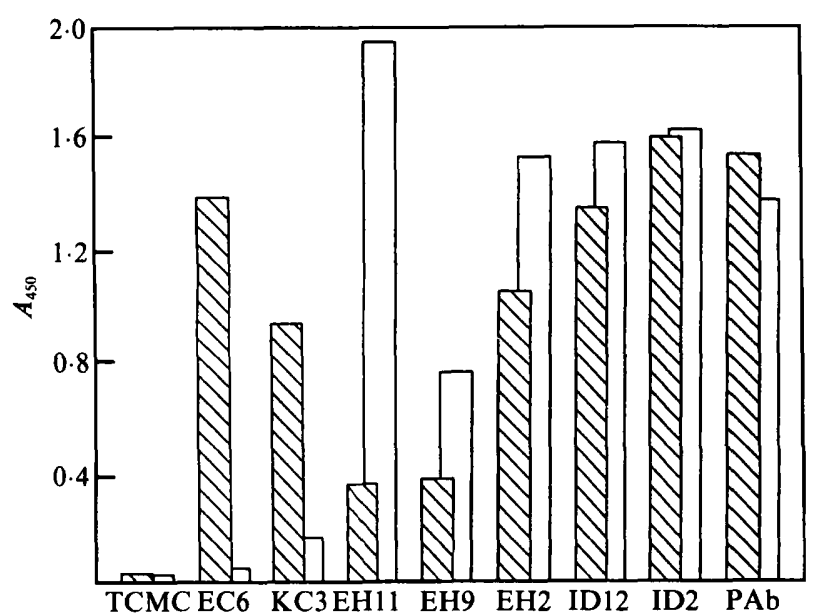

Fig. 1. Ability of MAbs to detect antigens of $\boldsymbol{H}$. lanuginosa in inoculated grain. Absorbance values are those given by ELISA with diffusates from inoculated $(\mathbb{\nabla})$ and control $(\square)$ rough rice grains tested against MAbs from several hybridoma cell lines and against polyclonal antibodies (PAb).

Table 4. Detection by ELISA using MAb EC6 for the presence of $H$. lanuginosa in rice samples

Results are expressed as the percentage of grains that gave absorbance values two, three, five and ten times greater than the control absorbance values. Controls were grains of each type incubated with tissue culture medium instead of MAb EC6.

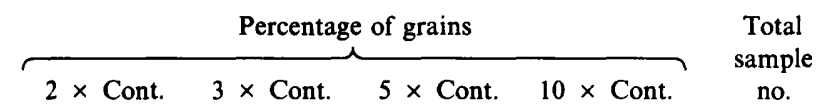

Rough rice

'Good' rice

Naturally infected

Inoculated

Brown rice

'Good' rice

Naturally infected

Inoculated

White rice

'Good' rice, samples $a, b, c, d, e$ and $f^{*}$

Indonesian inoculated with $P$. islandicum

Naturally infected selected yellow grains

Water-jacket experiment

$$
\text { Time (d) Depth (cm) }
$$

$\begin{array}{rr}0 & - \\ 4 & 3 \\ 4 & 12 \\ 10 & 3 \\ 10 & 12\end{array}$

-
3
12
3
12

$\begin{array}{rr}5 & \\ 51 & 26 \\ 100 & 100 \\ & \\ 35 & 7 \\ 78 & 6 \\ 100 & 100\end{array}$

$\begin{array}{rr}0 & 0 \\ 26 & 16 \\ 100 & 100\end{array}$

$75 \quad 0$

$61-26$

$100 \quad 98$

0

100

0

98

0

78

98

$\begin{array}{rr}80 & 35 \\ 100 & 100 \\ 100 & 100 \\ 100 & 100 \\ 100 & 88\end{array}$

0

3

90

35

100

100
88

$\begin{array}{rrr}0 & 0 & 40 \\ 0 & 0 & 40 \\ 73 & 29 & 80\end{array}$

40
160
40

40

80

40

40

40

80

*'Good' rice samples were as follows: $(a)$ from Indonesia; $(b)$ from the Philippines; $(c)$ supermarket Basmati; (d) supermarket long grain; $(e)$ commercial sample inoculated with Penicillium sp. XCII; $(f)$ commercial sample inoculated with $P$. islandicum.

several of the test fungi. There was no common pattern but one cell line, EH11, secreted MAbs that did not recognize antigens from any of the seven Penicillium species but did cross-react with antigens from six of the seven species of aspergilli. With the exception of $A$. flavus, absorbance readings for MAb EH11 tested against aspergilli were higher than those with $H$. lanuginosa 
C I

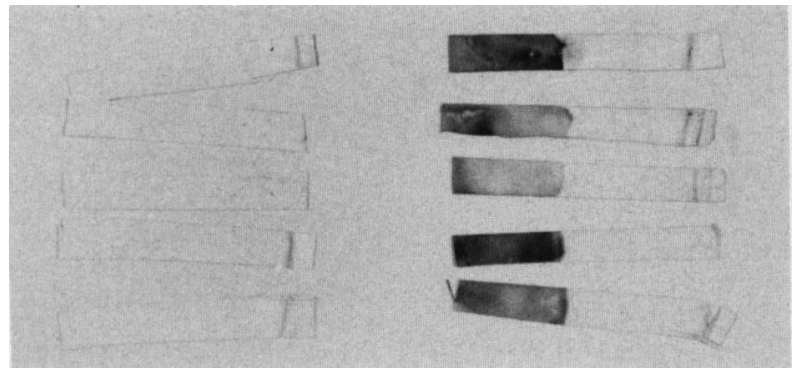

Fig. 2(a)

(i)

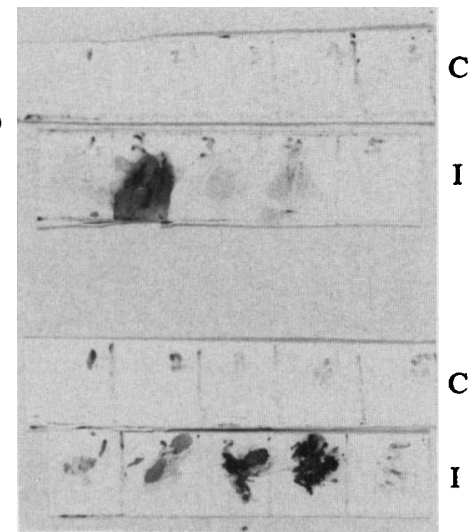

Fig. 2(b)

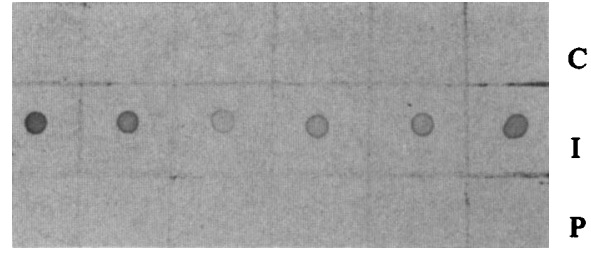

Fig. 2(c)

Fig. 2. (a) DIP-STICK immunoassays of diffusates from rough rice grains probed with MAb EC6. (b) SQUASH-BLOT immunoassays of outer (i) and inner (ii) husks of rough rice grains probed with MAb EC6. (c) DOT-BLOT immunoassays of diffusates from brown rice samples probed with MAb EC6. I, Rice grains inoculated with $\boldsymbol{H}$. lanuginosa; $\mathrm{C}$, control rice grains - not inoculated; $\mathrm{P}$, rice grains inoculated with Penicillium sp. XCII.

(Table 2). Two cell lines were more specific; ID12 cross-reacted only with Corynascus sepedonium and EC6 cross-reacted with $C$. sepedonium, Penicillium diversum var. aureum and $P$. variabile. The three isolates of the unnamed species of Penicillium, X8, XCII and DFNG, reacted differently with MAbs from different cell lines.

Nearly all the MAbs raised in this fusion were IgM antibodies but two of the three relatively specific MAbs, ID12 and EH11 were IgG antibodies of subclasses IgG1 and IgG2a respectively (see Table 2).

Heat treatment of surface washings reduced slightly the reactivity of all MAbs. However, the reactivity of $\mathrm{KC} 3$ and EC6 was reduced to one-tenth that of the untreated (Table 3).

Periodate treatment of surface washings had no significant effect on the reactivity of MAbs EH9, IG12 and EH2, but decreased considerably the reactivity of MAbs EC6, EH11 and KC3 and increased slightly the reactivity of ID2.

\section{Development of diagnostic assays}

ELISA. Several methods of extracting and detecting fungal antigens from inoculated grains were explored. Considerable problems were encountered; most MAbs [but not control tissue 


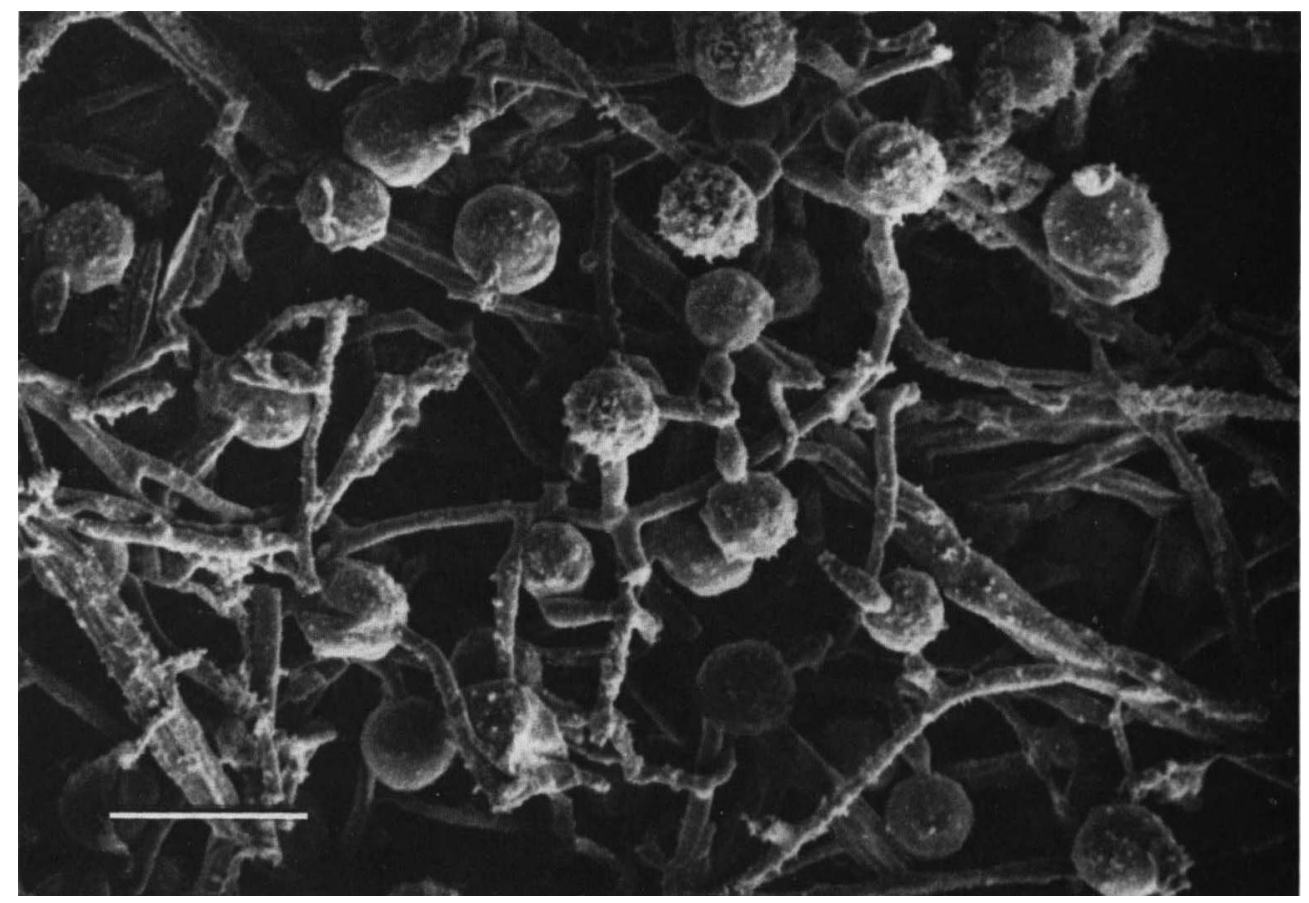

Fig. 3. SEM of spores and mycelium from a 5-d-old YSA culture of $H$. lanuginosa. Bar, $20 \mu \mathrm{m}$.

culture medium (TCMC)] cross-reacted with host tissues giving absorbance values that were often higher with extracts from control than infected material. Grinding of the grains in PBS proved particularly unsatisfactory (results not shown) even at high dilutions and with the addition of a $1 \mathrm{~h}, 3 \%(\mathrm{w} / \mathrm{v})$ BSA block between primary and secondary antibodies. The most successful method involved passive coating of microtitre wells with diffusates from individual grains that had been soaked overnight in PBS, in single wells using $150 \mu \mathrm{l}$ volumes per well. One cell-line, EC6, clearly distinguished grains of inoculated rough rice from control grains (Fig. 1). When naturally infected grains were tested with EC6 by this method, approximately $25 \%$ of the grains tested positively but absorbance values were much lower than for inoculated grains (Table 4).

DOT-BLOT, DIP-STICK and SQUASH-BLOT assays. Clear differences were detected between control (C) and inoculated (I) grains when prewetted strips of membrane (DIPSTICKS) were left to soak overnight in Eppendorf tubes containing rough rice grains and PBS and tested with the MAb EC6 (Fig. $2 a$ ). About $10 \%$ of naturally infected grains tested positively by this method (not shown). When the same soaked grains were squashed directly onto the membrane, either before (i) or after removal of the husk (ii), positive imprints could also be seen (Fig. 2b); more intense reactions appeared to be associated with the inner surface. In a separate similar experiment with brown rice grains, inoculated either with $H$. lanuginosa or the Penicillium sp., diffusates from the Humicola-inoculated rice grains, spotted onto PVDF membranes and reacted with MAb EC6, gave positive spots (Fig. 2c) but droplets from uninoculated grain or grain inoculated with the unidentified Penicillium isolate XCII, did not. The same results were obtained with droplets from inoculated and control rough rice grains (not shown).

Scanning electron micrographs of infected and healthy grains. SEM studies of spores of $H$. lanuginosa from 5-d-old YSA cultures and from inoculated grain showed the very characteristic ornamented spore coat (Fig. 3 and Fig. $4 a, b$ ). Wefts of mycelium and immense numbers of spores were seen by SEM in inoculated grains both on the outer and inner surfaces of the husks (Fig. $4 a, b$ ), particularly in the groove and embryo regions and, to a lesser extent, on the surface 

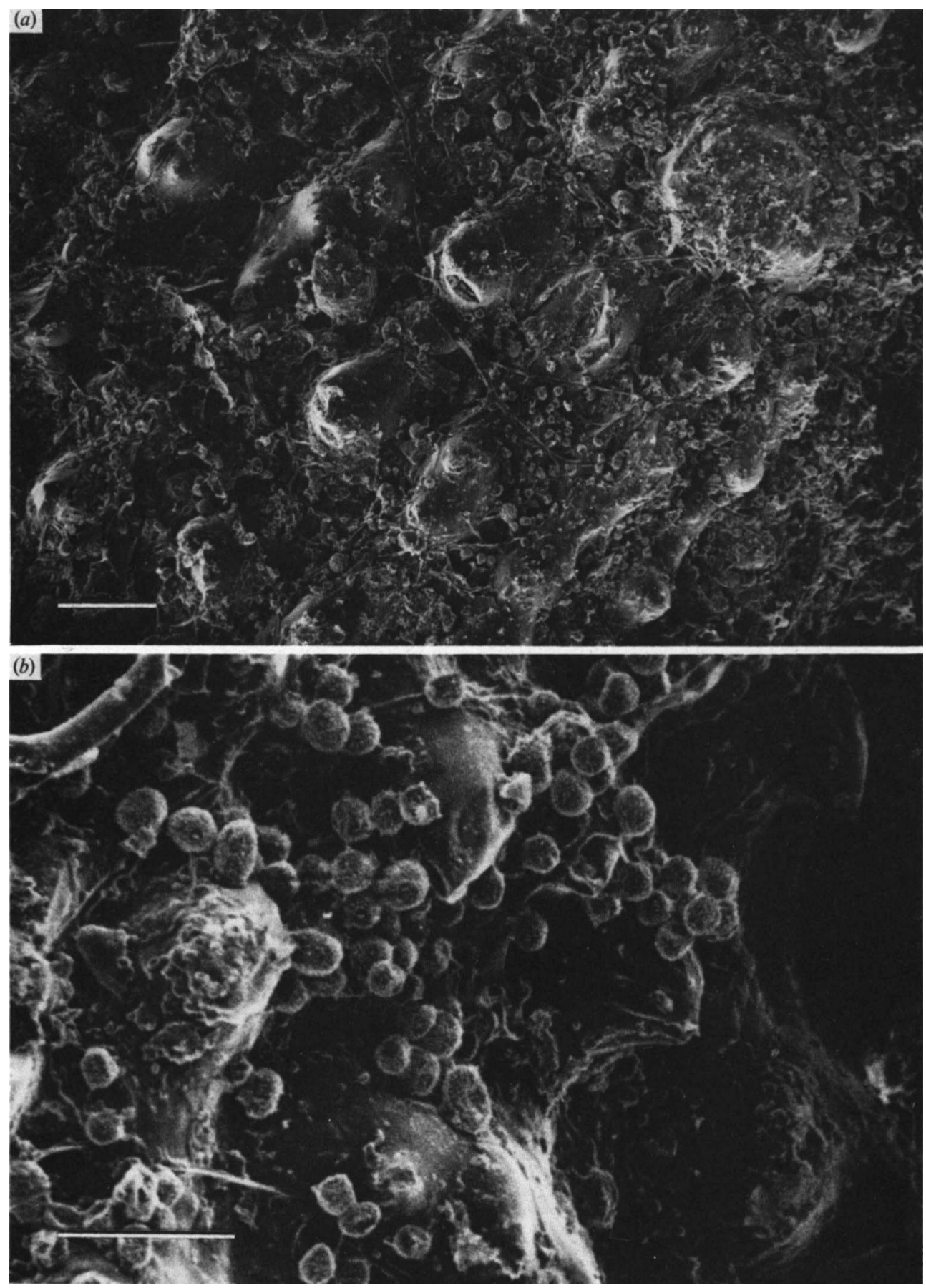

Fig. $4(a, b)$. SEM of rough rice grain inoculated with $H$. lanuginosa. Bars: $40 \mu \mathrm{m}(a) ; 20 \mu \mathrm{m}(b)$.

of the rice grain. Some spores of $H$. lanuginosa were also seen on the outer surfaces of the husks of some 'good'grains (Fig. 5a,b) but little mycelium and few spores were found on the inner surface of the husk or the grain itself. Similarly, spores and mycelium were found in naturally infected grains but very much less than in inoculated grains (Fig. $6 a$ ). In naturally infected grains the 

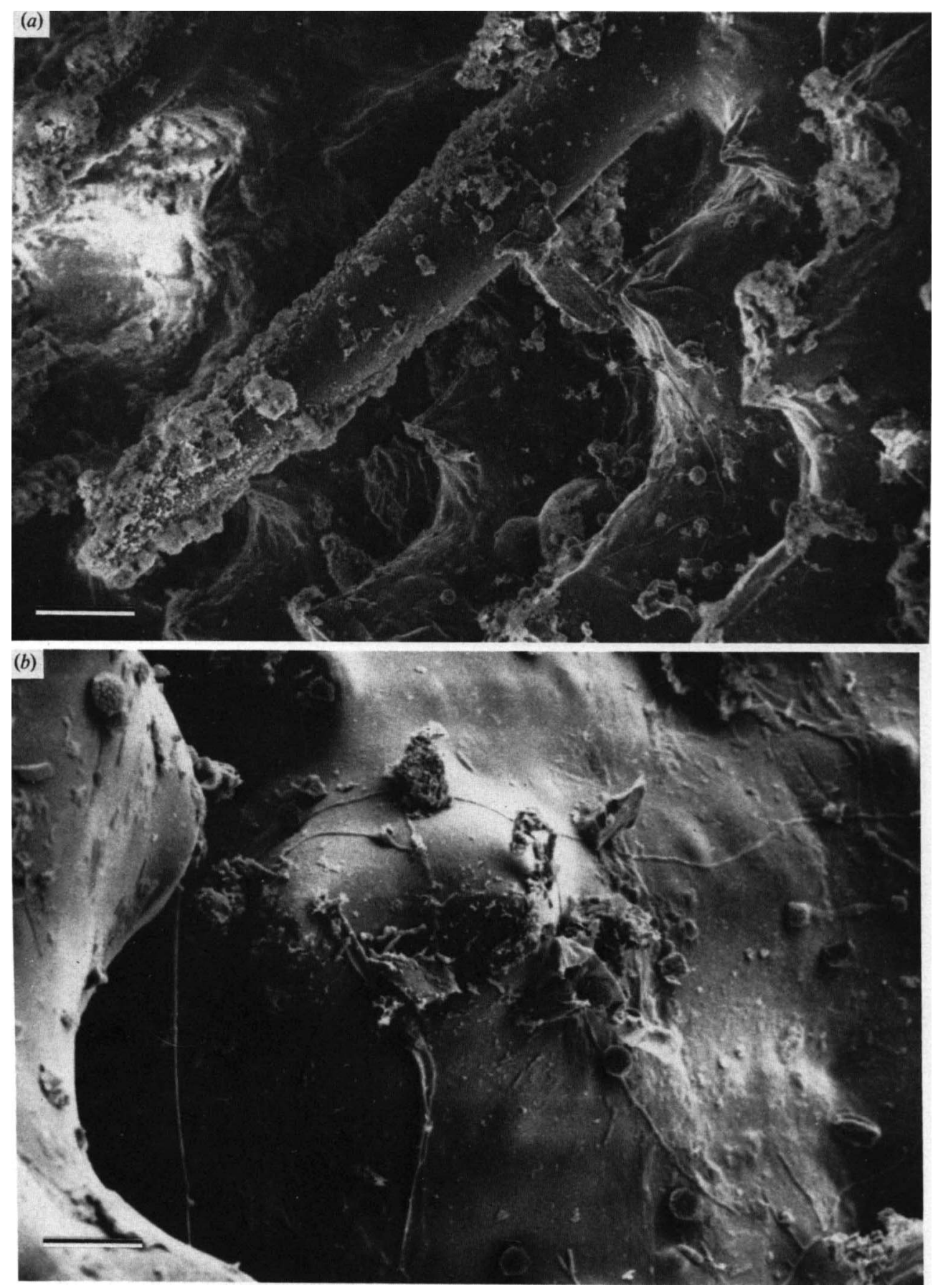

Fig. $5(a, b)$. SEM of uninoculated 'good' rough rice grains with a few spores of $\boldsymbol{H}$. lanuginosa. Bars: $20 \mu \mathrm{m}(a) ; 10 \mu \mathrm{m}(b)$.

inner surface of the husks (Fig. 6b) appeared to be more colonized than in inoculated grains. Several other fungi, actinomycetes and bacteria were noted in all the naturally infected grains examined but no one organism was present in any significant numbers or consistent pattern; nor were the organisms readily identifiable. 

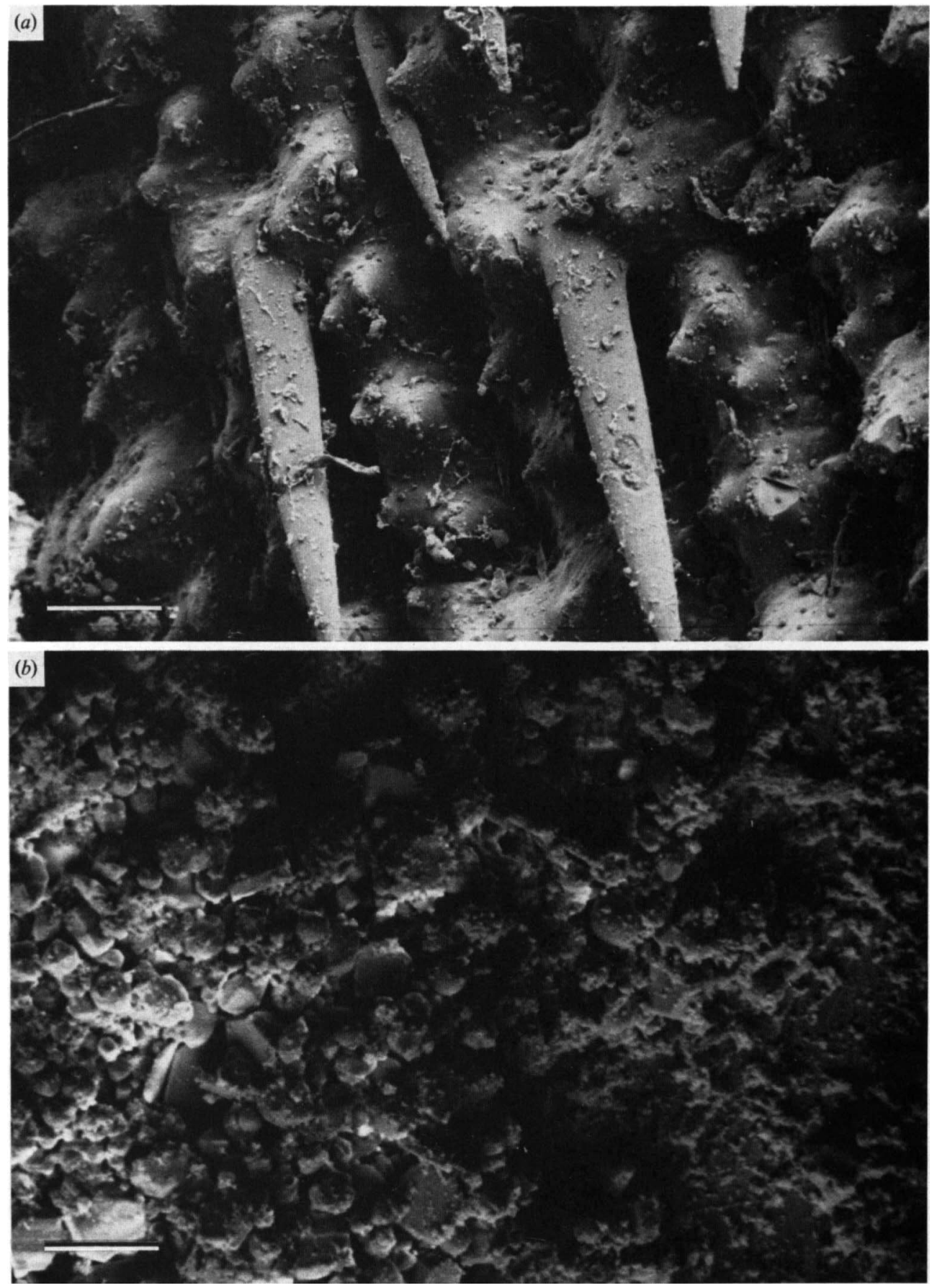

Fig. 6. Outer $(a)$ and inner $(b)$ surfaces of the husk of naturally infected rice grains. Bars: $40 \mu \mathrm{m}(a)$; $10 \mu \mathrm{m}(b)$.

\section{DISCUSSION}

In this study we have shown that saline surface washings of a solid culture of $H$. lanuginosa can be used directly, without concentration or Freund's adjuvant, both as an immunogen and as a source of antigens to screen hybridoma supernatants for species-specific MAbs. This very 
simple method reduces considerably the effort involved in raising species-specific hybridomas to fungi. It also provides a mechanism for raising MAbs to surface molecules that are easily removed and therefore negates lengthy extraction procedures in diagnostic assays to detect the fungus in or on its natural substrate/host. It is not known if this method can be used with all fungi that can be grown in vitro but it has been used equally successfully by the authors to raise a species-specific MAb to Penicillium islandicum (unpublished). Kaufman \& Standard (1987) and Polonelli et al. (1986) have used a similar method to raise antibodies to mycopathogens. However, their method was more complex and was not necessarily limited to surface molecules. They included merthiolate in the bathing solution and allowed this solution to completely cover the surface of agar slant cultures overnight. Almost certainly the merthiolate would cause membrane damage and allow leakage of intracellular substances.

The exact site and nature of species-specific antigens within the fungal hypha has not yet been determined but is the subject of a continuing project. However, from this study certain trends are apparent that are consistent with other immunological studies of fungi and Rhizobium (Dewey $e t$ al., 1989; Notermans et al., 1987; Brewin et al., 1986). Of the 12 hybridoma cell lines grown in bulk that secreted MAbs recognizing surface molecules of $H$. lanuginosa, only three secreted antibodies of class IgG; the others all produced IgM antibodies.

The sensitivity of EC6 antigens to autoclaving and prolonged periodate treatment suggest that the antibody is recognizing the carbohydrate region of a glycoprotein (cf. Wycoff et al., 1987).

Little correlation was found between fungal specificity of MAbs for $H$. lanuginosa (i.e. speciesspecificity) and cross-reactivity with the host. Ten out of 12 of the MAbs grown in bulk, including all three of the IgG antibodies, cross-reacted with diffusates from non-infected rice grains (Fig. 1). Of the two that did not cross-react one, KC3, cross-reacted with several of the other test fungi but not $H$. insolens (Table 2). The other, EC6, cross-reacted with only three of the 21 test fungi, namely Corynascus sepedonium, $P$. diversum var. aureum and $P$. variabile. Fortunately, these three fungi are not associated with the yellowing of rice grains. The two Penicillium species are more often isolated from grain stored for long periods.

Parallel ELISA tests and culture-isolated assays on artificially inoculated and control grains (water-jacket experiment) established that the MAb EC6 can be used effectively to detect the presence of $H$. lanuginosa in grains. However, some difficulty was experienced in deciding where to set the positive threshold absorbance value. In the above studies, where 4-d-old inoculated material was sampled at a depth of $3 \mathrm{~cm}, 40 \%$ of the grain was found to be infected by conventional surface-sterilization and plating-out techniques (data not shown). This figure is almost certainly an underestimate because it does not reflect the surface growth of the fungus on the husks. In ELISA tests on equivalent material absorbance values that were three, five and ten times control values indicated $100 \%, 89 \%$ and $51 \%$ levels of infection respectively. SEM studies confirmed the presence of a great quantity of both mycelium and spores on the surfaces of all inoculated grains. The only limitation to the use of MAb EC6 might be that it detects both live and dead fungal material; in some instances this could be considered an advantage. Plating-out of samples taken at a depth of $12 \mathrm{~cm}$ from 10-d-old inoculated material showed that none of the fungal material remained alive but ELISA absorbance values (three times greater than the controls) indicated the presence of fungal material in $88 \%$ of the samples.

ELISA tests enabled us to test far greater quantities of naturally infected grain than is feasible by conventional isolation procedures. Much lower values of fungal infection were found in naturally infected grain than in inoculated material. Absorbance values three times greater than the control for naturally infected rough rice and brown rice indicated $26 \%$ and $61 \%$ levels of infection respectively. SEM studies confirmed that less fungal material was present in naturally infected grain. Absorbance values for 'good' white rice were at background levels but an ELISA test on 'good' rough rice indicated that a small percentage $(5 \%)$ of grains had either a low level of infection (twice the control) or were contaminated with spores. This was also confirmed by SEM studies where a few $H$. lanuginosa spores were seen on the surface of some grains. No recognizable fungal material could be seen on the surfaces of hand-selected yellow grains but ELISA tests indicated $90 \%$ infection in these samples. This could suggest either that the 
mycelium and spores are present but morphologically distorted by the milling process or that only fungal products are present.

Slightly lower figures were obtained for percentages of infection by the DIP-STICK assays but incubation with primary or secondary antibodies for longer periods could possibly increase the sensitivity of these assays compared to that of the ELISA tests. The DIP-STICK assay is extremely simple to perform and requires no laboratory facilities. Extensive field assays could easily be done by this method and used to resolve the role of $H$. lanuginosa in the yellowing process.

The authors acknowledge the valuable discussions with R. D. Cooke and P. J. A. Reilly in the preparation of this paper and the financial assistance of the UK Overseas Development Administration.

\section{REFERENCES}

BrewiN, N. J., Butcher, G. W., GALFRÉ, G., LaRkins, A. P., Wells, B., WoOd, A. E. \& ROBERTSON, J. G. (1986). Immunochemical analysis of the legume root nodule. In Immunology in Plant Science, Society for Experimental Biology series no. 29, pp. 155-170. Edited by T. Wang. Cambridge: Cambridge University Press.

Callow, J. A., Estrada-Garcia, M. T. \& Green, J. R. (1987). Recognition of non-self: the causation and avoidance of disease. Annals of Botany 60 (suppl. 4), 3-14.

Chard, J. M., Gray, T. R. G. \& Frankland, J. C. (1985). Use of anti-Mycena galopus serum as an immunofluorescent reagent. Transactions of the British Mycological Society 84, 243-249.

Christensen, C. M. \& Sauer, D. B. (1982). Microflora. In Storage of Cereal Grains and their Products, 3rd edn, pp. 219-240. Edited by C. M. Christensen. St Paul, Minn.: American Association of Cereal Chemists.

Clarke, J. H., MacNicoll, A. D. \& Norman, J. A. (1986). Immunological detection of fungi in plants including stored cereals. $C A B$ International Biodeterioration Supplement 22, 123-129.

CoOney, D. G. \& Emmerson, R. (1964). Thermophilic Fungi. San Francisco: W. H. Freeman.

Dewey, F. M. \& Brasier, C. M. (1988). Development of ELISA for Ophiostoma ulmi using antigen coated wells. Plant Pathology 37, 28-35.

DEWEY, F. M., BARRETT, D. K., Vose, I. R. \& LAMB, C. J. (1984). Immunofluorescent microscopy for detection and identification of propagules of Phaseolus schweinitzii in infested soil. Phytopathology 74, 291-296.

Dewey, F. M., Munday, C. J. \& Brasier, C. M. (1989). Monoclonal antibodies to specific components of the Dutch Elm disease pathogen Ophiostoma ulmi. Plant Pathology (in the Press).

Foung, S. K. H., SASAKI, D. T., GRUmet, F. C. \& Engleman, E. C. (1982). Production of functional human $\mathrm{T}-\mathrm{T}$ hybridomas in selection medium lacking aminopterin and thymidine. Proceedings of the National Academy of Sciences of the United States of America 79, 7484-7488.

Hardham, A. R., Suzaki, E. \& Perkin, J. L. (1986). Monoclonal antibodies to isolate-, species-, and genus-specific components on the surface of zoospores and cysts of the fungus Phytophthora cinnamomi. Canadian Journal of Botany 64, 311-321.

Kaufman, L. \& Standard, P. G. (1987). Specific and rapid identification of medically important fungi by exoantigen detection. Annual Review of Microbiology 41, 209-225.

Kennett, R. H., Denis, K. A., Tung, A. S. \& Klinman, N. R. (1978). Hybrid plasmacytoma production: fusion with adult spleen cells, monoclonal spleen fragments, neotonal spleen cells and human spleen cells. Current Topics in Microbiology and Immunology 81, 77-91.

KOHLER, G. \& MILSTEIN, C. (1975). Continuous culture of fused cells secreting antibody of predefined specificity. Nature, London 256, 495-497.

Notermans, S., Wieten, G., Engel, H. W. B., Rambouts, R. M., Hoogerhout, P. \& van BoOM, J. H. (1987). Purification and properties of extracellular polysaccharide (EPS) antigens produced by different mould species. Journal of Applied Bacteriology 62, 157-166.

DE PADUA, D. B. (1977). A critical review of the losses in the rice post production system in some south east Asian countries. Workshop on Interfaces between Agriculture, Nutrition and Food Science, IRRI, Los Banos, Philippines, pp. 87-104.

Phillips, S. I., Mitfa, R., SNitha, S., Wallbridge, A. J., COOKE, R. D. \& BAKeR, A. A. (1984). A study of the factors involved in the post-harvest yellowing of rice. In Health and Ecology in Grain Post-harvest Technology, Proceedings of the 7th ASEAN Technical Seminar, Kuala Lumpur, Malaysia.

Phillips, S. I., Widjaja, S., Wallbridge, A. J. \& COOKE, R. D. C. (1988). Rice yellowing during post harvest drying by aeration and during storage. Journal of Stored Products Research 24, 173-181.

PITT, J. I. (1979). The Genus Penicillium and its Teleomorphic States Eupenicillium and Telaromyces. London: Academic Press.

Polonelli, L., Castagnola, M. \& Morace, G. (1986). Identification and serotyping of Microsporum canis isolates by monoclonal antibodies. Journal of Clinical Microbiology 23, 609-615.

RorTt, I. (1984). The Immune Response. II. Future Aspects. In Essential Immunology, pp. 87-127. Oxford: Blackwell Scientific Publications.

UMRATH, W. (1974). Cooling for rapid freezing in electron microscopy. Journal of Microscopy 101, 103105.

WyCOFf, K. L., Jellison, J. \& AYers, A. R. (1987). Monoclonal antibodies to glycoprotein antigens of a fungal plant pathogen, Phytophthora megasperma f.sp. glycinea. Plant Physiology 85, 508-515. 